\title{
NOSTALGIA E EXÍLIO: O INTELECTUAL CATÓLICO GALVÃO DE SOUSA E A IDEIA DE "HISPANIDADE"
}

\author{
Nostalgia and exile: The catholic and intellectual \\ Galvão de Sousa and the idea of "Hispanidade"
}

\author{
Marcos Gonçalves*
}

\begin{abstract}
RESUMO
O artigo discute a ideia de "hispanidade" desenvolvida em parte da reflexão do intelectual católico José Pedro Galvão de Sousa (19121992). Requisitado nos círculos católicos tradicionalistas, monárquicos e integristas de ambientação ibérica, Galvão de Sousa é um dos difusores desse pensamento no Brasil. Nostálgico dos regimes monárquicos e teórico do corporativismo, o intelectual em questão busca lugar para uma concepção de mundo que se defronta perante um amplo cenário de mudanças ideológicas e doutrinárias estabelecidas nas décadas de 1960-70: o avanço da teologia da libertação, o Concílio Vaticano II e, num contexto histórico mais imediato, a ditadura militar brasileira.

Palavras-chave: Galvão de Sousa; intelectuais católicos; hispanidade e tradição hispânica.
\end{abstract}

\begin{abstract}
The article discusses the idea of "Hispanidade" partly based on the reflections of the intellectual and catholic José Pedro Galvão de Sousa (1912-1992). Highly in demand within traditional catholic, royalists and Iberian-related "integrist" circles, Galvão de Sousa is one of the broadcasters of that thought in Brazil. Nostalgic of monarchic regimes and a theoretical thinker of corporatism, the intellectual in question searches a place for a conception of world that faces a wide scenario of ideological and doctrinarian changes established on the sixties and seventies comprising the advance of theology of freedom, the Second
\end{abstract}

* Doutor em História. Professor Adjunto da Universidade Estadual do Paraná - UNESPAR. 
Vatican Council, and, in a more immediate historical context, the Brazilian military dictatorship.

Key-words: Galvão de Sousa; Catholic intellectuals; Hispanidade and Hispanic tradition.

\section{Intelectuais e intelectuais católicos}

Um dos desafios mais comuns na análise sobre o papel do intelectual é o empenho em classificá-lo num quadro teórico adequado a responder quais as demandas que chamam por suas funções na sociedade. A capacidade de sua palavra/ação interagir quanto aos valores que permanecem estáveis, se modificam ou são rompidos dentro de um sistema cultural e de suas relações mais gerais solicitaria a colocá-lo num lugar social, mesmo que impreciso e, portanto, movediço, designado como intermediário. Consideradas as várias maneiras de se operar as problemáticas que regem a História intelectual, o historiador e sociólogo Carlos Altamirano recentemente assinalou que essa história não possui em seu âmbito uma linguagem teórica ou modos de proceder que funcionem como modelos obrigatórios nem para analisar, nem para interpretar seus objetos ${ }^{1}$. E isto se reproduz, em maior ou menor grau, prossegue Altamirano, dada a erosão pela qual passam as disciplinas das ciências humanas e, de modo particular, a correspondente dispersão teórica e fuga das totalidades de que é alvo a prática historiográfica. Pascal Ory, ao estudar a história dos intelectuais franceses entre os séculos XIX e $\mathrm{XX}$, procurou transgredir o ecletismo dominante definindo a sociologia e a ética como dois campos consagrados para a análise dessa história. Mas, tangenciando-as ao reconhecer algumas de suas limitações, derivou para uma terceira via, ou uma estratégia metodológica intermediária que confere importância à articulação recíproca dos dois campos.

Se para a sociologia, como acentua Ory, o termo "intelectual" concretamente propenderia aceitá-lo vinculado a estruturas socioprofissio-

1 ALTAMIRANO, Carlos. Ideias para um programa de História intelectual. Tempo Social, revista de Sociologia da USP, v. 19, n. 1, p. 9, junho 2007. 
nais e num âmbito no qual se destaca um duplo setor: da informação e da educação; a acepção ética ou ético-ideológica diria respeito à capacidade de intervenção no terreno da política, entendida no sentido de debate sobre as coisas do mundo e da sociedade. Nesta acepção, a intervenção do intelectual deverá ser manifestamente pública:

No será el hombre que piensa, sino el hombre que comunica un pensamiento: influencia interpersonal, petición, tribuna, ensayo, tratado. Y en su contenido la manifestación intelectual será conceptual, en el sentido de que suponará el manejo de nociones abstratas. No habrá ninguna necesidad de producir los conceptos en cuestión. Su uso bastará ${ }^{2}$.

Tal descrição convida a compreender o intelectual, segundo Ory, como portador de uma missão: o confessor, tradutor e mártir dos seus princípios. No entanto, acompanhando a mesma reflexão, o caminho intermediário aponta para um amálgama que interpreta a ação do intelectual como um ser investido no cultural, criador e mediador, colocado em situação de homem do político, produtor ou consumidor de ideologia: "Se tratará de un estatus, como en la definición sociológica, pero trascendido por uma voluntad individual, como en la definición ética, y orientado a un uso colectivo"'.

Se a questão é colocada nos termos propostos por Norberto Bobbio, seria pensada com relativa aproximação às dimensões analíticas sugeridas por Ory. Bobbio, conhecedor das ambiguidades que cercam o objeto e sua história, indagou até que ponto existe uma definição restritiva quanto à natureza e à função do intelectual ? $^{4}$ Bastaria, seguindo o filósofo italiano, que os intelectuais fossem consignados como depositários de um único corpo de doutrinas ${ }^{5}$ É normal, todavia, que o arquétipo de intelectual pareça quase sempre estar circunscrito pela sua relação de distância ou proximidade com o poder político. É esta, talvez, a relação mais antiga,

2 ORY, Pascal; SIRINELLI, Jean-François. Los intelectuales en Francia. Del caso Dreyfus a nuestros días. Trad. Evelio Miñano. València: Universidad de Valéncia, 2007, p. 20.

3 Ibid., p. 21. Grifo no original.

4 BOBBIO, Norberto. Os intelectuais e o poder: dúvidas e opções dos homens de cultura na sociedade contemporânea. Trad. Marco Aurélio Nogueira. São Paulo: UNESP, 1997.

$5 \quad$ Ibid., p. 116. 
pelo menos, desde Zola e o manifesto J'Accuse!, que confere ao intelectual o status de independência, autonomia, onipresença, requisitado e militante sem vínculos com a opacidade das ideologias, diga-se, quase uma ficção; ou o intelectual que exerce as funções de conservação, moralmente zeloso e vigilante quanto à manutenção de uma determinada ordem social, ou refratário às potencialidades alternativas em sua cultura. No dizer de Gerard Leclerc, esta função de conservação é desempenhada pelos designados guardiões da tradição, podendo-se admitir que os conservadores sejam a consciência do grupo e proíbam, enquanto defensores dos valores e religião estabelecidos, os "desvios heterodoxos" que apontam contra o particularismo e o etnocentrismo estreito da sociedade ${ }^{6}$. Este argumento serviria como classificação adequada, suficiente ou mais ou menos precisa para o termo "intelectual católico"?

A interrogação comporta alguns níveis de respostas mesmo que parciais. Na vertente conservadora - que tem por emulação valores transcendentes e permanentes, e nesta perspectiva específica, ligada às religiões institucionais - estaria situada, ressalvadas as indeterminações e incertezas epocais, a intelectualidade católica conectada por sentimentos de fidelidade a uma parte da Igreja que resistiu ou recusou não somente as renovações propostas pelo Concílio Vaticano II (1962-1965), mas, igualmente, adotou uma postura intransigente quanto ao "progressismo católico" e a um dos seus desdobramentos mais imediatos na segunda metade do século XX: a teologia da libertação. Nesta vertente tradicionalista, sobressaem, em sua dimensão política, pela ordem, o discurso visceralmente antiliberal, antiparlamentarista e anticomunista, e, no espectro religioso, um antimodernismo robustecido pelo anticonciliarismo que veio a ser desenvolvido mais eficazmente depois de 1965.

Nesta vertente, caberiam os intelectuais nostálgicos de uma cristandade medieval defensores de uma continuidade com a cultura ibérica na forma de uma comunidade hispânica transnacional: católica e monárquica, na qual se destaca a ideia de "hispanidade" como estilo, ethos, espírito. Esta comunidade seria liderada pela Espanha, secundada por Portugal e abarcaria culturalmente as Américas espanhola e portuguesa. A continuidade

6 LÉCLERC, Gerard. Sociologia dos intelectuais. Trad. de Paulo Neves. São Leopoldo: Unisinos, 2004. p. 24-25. 
defendida ainda presumiria a comunidade organizada em oposição às culturas da modernidade, de influência anglófona ou francesa que hibridizam soluções não necessariamente complementares: o protestantismo, o republicanismo (socialista e liberal), as assembleias parlamentares, derivando desses elementos o que os tradicionalistas resumem como um dos aspectos da "europeização". É nesta vertente tradicionalista, pois, e que exerce a função de conservação, o lugar no qual se alojam o pensamento e a ação do jurista, escritor e professor brasileiro objeto desta discussão: José Pedro Galvão de Sousa.

A inserção de Galvão de Sousa dá-se em um grupo - católicos tradicionais - que, sem ser homogêneo, comunga de conceituações gerais sobre valores pressionados a serem rompidos na sua dimensão imutável de princípios defendidos pelo grupo por meio de suas respectivas redes de pertencimento, como o periodismo, as faculdades católicas e organizações congêneres. A categoria na qual está circunscrita o grupo se alicerça no legado conceitual produzido desde o século XVIII pelas várias fontes do conservadorismo e do tradicionalismo católicos. Porém, conforme a leitura operada pela geração de intelectuais católicos à qual está filiado Galvão de Sousa, seria um equívoco considerar alguns dos célebres "pais" do conservadorismo contemporâneo - como Burke, Maistre, Bonald, Donoso Cortés e outros - inscritos numa linha de pensamento ausente de descontinuidades e oscilações. Embora os pioneiros do conservadorismo possam ser vistos como provedores de textos canônicos e de matrizes filosófico-doutrinárias, a tais linhas se associam camadas de significados temporais atribuídas por tradições intelectuais correlatas - Vilfredo Pareto, Carl Schmitt, Charles Maurras, Menéndez Pelayo, Ramiro de Maeztu, o tardio Manuel García Morente - que, além de contribuírem para uma metamorfose na anatomia do intelectual conservador, foram decisivos para submeter as ideologias do século XIX a um brutal processo de revisão no século XX, como bem frisou o cientista político Luis Gonzalo Díez ${ }^{7}$. Tais mudanças fizeram o intelectual conservador - e, no mais das vezes, católico - assumir ora posições mais moderadas, ora posições mais intolerantes e radicalizadas, em face

7 DÍEZ, Luis Gonzalo. Anatomía del intelectual reaccionario: Joseph de Maistre, Vilfredo Pareto y Carl Schmitt. La metamorfosis fascista del conservadurismo. Madrid: Editorial Biblioteca Nueva, 2007. p. 18. 
de avanços e recuos de fenômenos sociais de várias ordens que assomaram na segunda metade do século $X^{8}$. Não obstante, é necessário mencionar, de um lado, a existência de uma base reflexiva e legitimadora geral e, de outro, a constituição de fundamentos de ação específicos, ambos complementares e mediados pelo catolicismo. A primeira sinaliza para a crítica ao mundo emergido do humanismo da renascença e da reforma protestante, tendo culminado, finalmente, sob a ótica conservadora, na revolução de 1789. A partir daí, o pluralismo das culturas políticas teria produzido uma espécie de normatividade abstracionista e degenerada pelo contratualismo intrínseco às democracias modernas, ao desfazer o arcabouço religioso e jurídico do jusnaturalismo. Os fundamentos de ação específicos se referem ao modo como foram constituídas as esferas de desencanto e pessimismo diante das modernidades múltiplas e de como certos intelectuais católicos, mergulhados nos dilemas de sua cultura, atribuíram valores e significados a tais especificidades: com quais correntes dialogaram, de quais correntes se distanciaram, que razões de natureza teórica, política e religiosa ainda sobrevivem ou adquiriram novos sentidos? É neste âmbito de problemas, sem, evidentemente, esgotá-los, e alguns brevemente elencados, que almejo instalar o pensamento de José Pedro Galvão de Sousa. Cauteloso quanto às generalizações ou excessos, pretendo verticalizar este exercício de análise, principalmente, a partir de uma linha de ação bem definida que marcou parte da reflexão de Galvão de Sousa sobre a cultura: os argumentos que o levaram a defender um tipo bem particular de tradição "hispânica", diferenciando-a das noções de iberismo ou tradição ibero-americana. Sobretudo, minha estratégia argumentativa será problematizada em relação aos seguintes contextos: as décadas de 1960/70, nas quais ressaltam os conflitos doutrinários entre "católicos tradicionalistas" e "católicos progressistas", e um contexto que chamaria de metodológico, pelo qual é possível colocar em causa os modos dominantes de interpretação do que é designado de iberismo ou tradição ibero-americana.

8 Não será preciso insistir que tais "fenômenos" sociais se associam aos processos revolucionários e descolonizadores em partes das Américas, Ásia e África; à implantação de ditaduras militares nas Américas Central e do Sul; e aos novos mercados de bens religiosos abertos a partir de uma perspectiva mais competitiva sobre a partilha desses bens da qual fez parte, sobretudo, a Igreja católica depois das deliberações do Concílio Vaticano II. 


\section{Galvão de Sousa e os usos da tradição: qual tradição?}

Para as inteligências estabelecidas, a produção intelectual de Galvão de Sousa seria como o personagem, uma obra improvável situada entre a nostalgia e o exílio: ou destinada ao confinamento ou endereçada a círculos bem restritos e passadistas. No entanto, seu pensamento aos poucos vem se constituindo em objeto de revisão e recuperação da parte de seus ex-alunos e de estudiosos interessados nas correntes ideológicas conservadoras, e as interpretações, gradativamente, ecoam, pelo menos em países como Brasil e Espanha. Além da tese de doutoramento defendida na Universidade de Córdoba (Espanha) por José J. Albert Márquez, de publicação recente, outros trabalhos indicam as variações temáticas tornadas possíveis por conta da interdisciplinaridade presente na reflexão tradicionalista de Galvão de Sousa9 .

Nascido em 1912, desde jovem, pelos caminhos pessoal e profissional traçados, Galvão de Sousa esteve engajado às correntes intelectuais católicas que, a partir da década de 1920, formaram a intelligentsia restauradora, que, para mais ou para menos, seguiram a liderança do Cardeal do Rio de Janeiro, Sebastião Leme. Ligado precocemente à docência e participando como um dos fundadores da Ação Católica em São Paulo na década de 1930, é provável que Galvão de Sousa tenha tomado certa distância do

9 A filosofia do direito natural, a história, as noções de grupo intermediário e Estado corporativo, o tradicionalismo hispânico, o integrismo católico, a formação de uma comunidade transnacional baseada na cultura hispânica são alguns dos temas que servem de interesse para a reconstituição da obra de Galvão de Sousa. Cf. ANTOINE, Charles. O integrismo brasileiro. Trad. João Guilherme Linke. Rio de Janeiro: Civilização Brasileira, 1980. BARCELLOS, Marcos Cotrim de. O conceito de "grupo intermediário da sociedade" no pensamento de Galvão de Sousa - Autoridade e tradição na reação ultramontana no Brasil (1916-1978). In: JORNADA DE ESTUDOS HISTÓRICOS DO PROGRAMA DE PÓS-GRADUAÇÃO EM HISTÓRIA DA UNIVERSIDADE FEDERAL DO RIO DE JANEIRO, 4., outubro 2009, 14 p. Digit. DIP, Ricardo. (Org.). Tradição, revolução e pós-modernidade. Campinas: Millenium, 2001. DIP, Ricardo. Elogio a José Augusto César e a José Pedro Galvão de Sousa. Anales de la Fundación Elías de Tejada, Madrid, año I, p. 75-84, 1995. GARCIA, Clovis Lema. Elogio do Patrono José Pedro Galvão de Sousa. Anales de la Fundación Elías de Tejada, Madrid, año I, p. 63-74, 1995. GONÇALVES, Marcos. Outros olhares sobre a tradição ibero-americana: o intelectual Galvão de Sousa e a revista católica "Hora Presente". In: SEMINÁRIO NACIONAL DE HISTÓRIA: POLÍTICA E CULTURA \& POLÍTICA E SOCIEDADE, 2., Rio de Janeiro. Caderno de Resumos. Rio de Janeiro: Universidade Estadual do Rio de Janeiro, 2010, p. 65-66. MÁRQUEZ, José J. Albert. Hacia un Estado Corporativo de Justicia. Fundamentos del Derecho y del Estado en José Pedro Galvão de Sousa. Barcelona: Atelier: 2010. MÁRQUEZ, José J. Albert. Comunidad lusíada y sentido de la historia en la obra de Galvão de Sousa. Anales de la Fundación Elías de Tejada, Madrid, año XV, p. 145-157, 2009. 
grupo de Leme, bem como há poucos indícios de sua participação mais ativa na revista $A$ Ordem e no Centro Dom Vital, tidos como os dois principais núcleos de referência e difusão do pensamento católico nessa época. A restauração pretendida por Galvão situava-se em outro horizonte e, ao final da década de 1940, o encontro com o tradicionalista espanhol Francisco Elías de Tejada y Spínola ${ }^{10}$ foi decisivo para o desenvolvimento de uma visão de direito e de história que não abandonaria até sua morte, em 1992:

El año 1948 fue clave en la vida de José Pedro: traba conocimiento, que luego sería amistad fraternal hasta el final de la vida del profesor español, con Francisco Elías de Tejada [...] Desde ese momento, confirmadas sus coincidencias religiosas, políticas y jurídicas, José Pedro se convierte en abanderado del tradicionalismo ibérico en Brasil, toda vez que a sus lecturas de los integralistas portugueses (principalmente António Sardinha, que tanto le influyo) sumo desde entonces la de los tradicionalistas españoles, desde Juan Vázquez de Mella a Antonio Asparisi y Guijarro, de Juan Donoso Cortés a Enrique Gil Robles ${ }^{11}$.

Ao lado de Elías de Tejada e do português Fernando de Aguiar, Galvão de Sousa fundou em 1950 a revista de cultura bilíngue Reconquista. O periódico, de flagrante tendência restauradora e monarquista, além de Brasil, Espanha e Portugal, era distribuído na Argentina, Chile e Peru. As dificuldades de manutenção e a duração efêmera da revista levaram Galvão de Sousa a afirmar, em correspondência de janeiro de 1952 a Elías de Tejada, que a difusão do pensamento tradicionalista no Brasil se encontrava no "marco zero" em razão do imediatismo que alguns setores esperavam quanto à assimilação do projeto político e intelectual do grupo ${ }^{12}$.

A adesão sem reticências de Galvão de Sousa às teses do tradicionalismo veio a ocorrer no contexto em que se abriam para o catolicismo

10 Francisco Elías de Tejada y Spínola (1917-1978). Nasceu em Madrid e foi Professor Catedrático de Direito Natural e Filosofia do Direito nas Universidades de Murcia, Sevilla, Salamanca e Madrid. Intelectual associado ao pensamento tradicionalista espanhol e ao carlismo legitimista, sua obra foi recepcionada e difundida nos círculos católicos brasileiros de extração monárquica e tradicional pelo empenho de José Pedro Galvão de Sousa. Cf. <http://www.fundacioneliasdetejada.org/>. Acesso em: $22 / 01 / 2011$.

11 MÁRQUEZ, José J. Albert. Op. cit., p. 31.

12 Ibid., p. 34. 
possibilidades amplas de renovação, ao mesmo tempo em que eram revitalizados sob nova fisionomia conflitos ideológicos, doutrinários e teológicos que recolocavam antigos problemas entre "tradicionalistas" e "modernistas". Ao longo dos anos 1950, uma gradativa abertura para o diálogo com outras igrejas cristãs pode ser evidenciada, a modo de um catolicismo mais reformista ou socialmente preocupado com as demandas populares ${ }^{13}$. Igualmente, houve por parte de alguns setores da Igreja católica a iniciativa em colaborar de forma depurada com a ideologia desenvolvimentista do governo Juscelino Kubitschek, tendo os prelados em várias ocasiões reafirmado a necessidade de sanar as graves injustiças sociais ${ }^{14}$. Na década seguinte, receptivas a concepções teóricas provindas do campo marxista, as correntes "progressistas" do catolicismo brasileiro, então emergentes, organizadas em diversas associações (JUC, JOC, AP) $)^{15}$, defrontadas pela acelerada expansão do capitalismo industrial, a marginalização e miséria das populações e o intenso movimento demográfico campo-cidade, defenderam como proposta uma simbiose de socialismo cristão traduzido na forma da revolução brasileira. O produto mais imediato desse postulado foi o definitivo rompimento doutrinário e ideológico com os grupos tradicionalistas, impregnados de um catolicismo herdeiro da tradição situada entre as reformas tridentinas (1545-1563) e o Concílio Vaticano I (1869-1870) e, ainda, radicalizados pelas orientações não dissipadas da luta contra o modernismo católico do início do século XX. Dois eventos localizados em topografias distintas vieram aprofundar a impossibilidade de consenso entre progressistas e tradicionalistas: o Concílio Vaticano II e o golpe militar de 1964. O primeiro, como afirma Beozzo, teria rompido com o monolitismo de posições dentro da Igreja católica, procurando reformar suas estruturas

13 Sobre as aproximações entre o protestantismo e o catolicismo no projeto de construção de um movimento ecumênico a partir de meados da década de 1950, cf. DIAS, Agemir de Carvalho. O movimento ecumênico no Brasil (1954-1994). A serviço da igreja e dos movimentos populares. Tese (Doutorado em História) - Universidade Federal do Paraná. Curitiba, 2007.

14 Assim se posiciona Riolando Azzi sobre a convivência entre os hierarcas da Igreja e o governo de Juscelino: “O projeto desenvolvimentista de Juscelino também contou com o apoio da instituição católica, apelando então os prelados pela necessidade de reformas sociais. Essa nova tomada de posição não foi motivada apenas pela solidariedade ao poder político, sendo também consequência de uma nova consciência a respeito da realidade brasileira". Cf. AZZI, Riolando. História da Igreja no Brasil: ensaio de interpretação a partir do povo. Tomo II/3-2. Terceira Época 1930-1964. Petrópolis: Vozes, 2008. p. 351.

Popular.

15 Respectivamente Juventude Universitária Católica, Juventude Operária Católica, Ação 
internas, remodelar a liturgia, acentuando a necessidade de um ecumenismo a partir do diálogo inter-religioso ${ }^{16}$. Claro está que as mudanças internas na Igreja brasileira não se limitavam à possível influência das deliberações do Concílio, mas também aos resultados políticos advindos do golpe militar de 1964, tendo em vista a importância assumida pelos católicos, contra ou a favor do golpe, no contexto que o precedeu. Combinados, o Vaticano II e a ditadura militar brasileira iriam povoar o imaginário das correntes católicas de representações que franqueavam a luta pelo monopólio das fontes de poder social:

Focos de resistência no interior do episcopado, dos teólogos mais tradicionais e de importantes parcelas da opinião pública em determinados países contrastaram com a entusiasta recepção da reforma conciliar por setores majoritários do catolicismo. [...] [O Concílio] Abriu também um período de atrito, disputas e desilusões na implementação das reformas, agravado pela insegurança jurídica. [...] O Concílio encaixava-se ainda em um período de dramáticas mudanças políticas e sociais no país. $\mathrm{O}$ fato de os bispos encontrarem-se regularmente ao longo dos quatro anos que antecederam a crise (1962-1963), com ela coincidiram (1964) e a sucederam (1965) - do início da década de 1960 ao golpe militar de 1964 - permitiu à instituição Igreja Católica situar-se, como corpo episcopal, em face dessas mudanças, como talvez nenhuma outra instituição ou grupo nacional, com exceção talvez dos militares ${ }^{17}$.

Não há dúvidas que grande parte do vértice da Igreja católica, através de seus mecanismos institucionais - hierarquia, intelectualidade, imprensa - e pelo militantismo de véspera organizado majoritariamente por leigos de uma classe média urbana, apoiou decididamente o golpe militar. A emblemática "Marcha da Família com Deus pela Liberdade", movimento que reuniu milhares de pessoas em algumas importantes capitais do país, capitalizou o tema do ateísmo do governo de João Goulart e sua suposta tentativa de implantação do comunismo, denunciando, da mesma forma, os

16 BEOZZO, José Oscar. A Igreja do Brasil no Concílio Vaticano II, 1959-1965. São Paulo: Paulinas, 2005. p. 51-61.

17 Idem, p. 51-61 
riscos do avanço da educação laica ${ }^{18}$. São importantes as referências de apoio ao golpe enunciadas por integrantes do clero regular. Um exemplo pode ser colhido nos editoriais de revistas como a Verbum, prestigioso periódico da Pontifícia Universidade Católica do Rio de Janeiro. Na edição de março/ junho de 1964, o jesuíta Francisco Leme Lopes, diretor de redação, assinava o editorial "O Brasil escolheu a Liberdade", no qual se destacavam trechos irrefutáveis de solidariedade ao movimento, visto como o "milagre de abril":

O Brasil marchou com Deus pela Liberdade. Cristo dissera um dia: "conhecereis a verdade e a verdade vos libertará" (João 8, 32). O povo da maior nação católica do mundo conhece a verdade da Revelação Divina: na fidelidade à sua vocação histórica encontrou a salvaguarda de sua independência. [...] O observador imparcial não pode deixar de reconhecer uma particular ação da Providência no "milagre de abril". A primeira vez no mundo inteiro em que o comunismo é vencido tão rapidamente sem se disparar um tiro, sem o sacrifício de uma só vida. Lição que é um estímulo para os povos que se veem dominados pela mais degradante das tiranias. [...] A rapidez da ação, a bravura das forças armadas, a clarividência dos governadores, tudo isso tornou possível a esplêndida vitória. Bem se viu que não passavam os comunistas de uma minoria extremamente ousada e ativa. Desmoronou-se como por encanto, como se fosse um castelo de cartas, o esquema por eles montado ${ }^{19}$.

Na conjuntura do catolicismo institucional, e ao contrário do argumento de Michael Löwy, não é que a "Igreja escolheu o campo das forças antidemocratas, autoritárias e conservadoras" ${ }^{20}$, posto que já se encontrava colocada nesse campo. Então, nesse novo contexto, muitos dos grupos que mantinham redes de pertencimento a comungarem mais ou menos as mesmas concepções de mundo de Galvão de Sousa - TFP, de Plínio Correia

18 Cf. CODATO, Adriano Nervo; OLIVEIRA, Marcus Roberto de. A marcha, o terço e o livro: catolicismo conservador e ação política na conjuntura do golpe de 1964. Revista Brasileira de História, São Paulo, v. 24, n. 47, p. 271-302, 2004.

19 LOPES, Francisco Leme, S. J. O Brasil escolheu a liberdade - Editorial. Verbum, Tomo XXI, p. 3-4, março/junho de 1964.

20 Cf. LÖWY, Michael. A guerra dos deuses. Religião e política na América Latina. Trad. Vera Lúcia Mello Joscelyne. Petrópolis: Vozes, 2000. p. 141. 
de Oliveira, e o grupo Permanência, liderado por Gustavo Corção - não teriam "(re)conceptualizado" a realidade de acordo com as mudanças que estavam acontecendo, optando por uma atitude de radical intransigência e pessimismo em face dessas circunstâncias ${ }^{21}$. Parece, assim, que o original do pensamento tradicionalista está em não ser compatível com nenhuma ou quase nenhuma das possibilidades que impliquem num redirecionamento dos símbolos da tradição, que, nesta perspectiva, deve ser tradição constituída, totalizante e absoluta e não tradição constituinte como recriação interpretativa: isto é, como uma coisa que, de forma contínua, reflete sobre si mesma $^{22}$. De modo que seu original, por paradoxo, talvez seja a consciência da sua "inatualidade" e, por conseguinte, denunciando crises e a persistir em defender atitudes restauradoras e autoritárias, bastante visíveis no programa intelectual do grupo no qual se insere Galvão de Sousa ${ }^{23}$.

Ao elencar seus pontos de vista num escrito de 1963, Galvão de Sousa se insurgia contra o progressismo, assumindo a posição de reacionário, na qual reiterava que, no fundo, progressismo e reacionarismo tratavam-se de duas concepções da filosofia da história a se defrontarem. Segundo Galvão de Sousa, os católicos progressistas tinham do progresso social e histórico uma ideia que os afastava das realidades sobrenaturais, aceitavam implicitamente certos postulados do progressismo naturalista e eram aderentes da política dos fatos consumados: "Nessa atitude de incoerência intelectual e de falta de virilidade, tacham de reacionários os que não

21 Koselleck propõe que os indivíduos estão sujeitos a reelaborar suas experiências através da linguagem histórica para dotá-las de novas formas e sentidos ou resistirem às mutações. Segundo Koselleck: "El significado de la palabra permanece constante, pero las circunstancias cambian, distanciándose del antiguo significado. La realidad asi transformada debe ser nuevamente conceptualizada". Além dessa possibilidade, Koselleck, inspirado nas concepções de Heiner Schultz, propõe outras três: 1) o significado da palavra, assim como o das circunstâncias apreendidas nela, permanecem sincrônica e diacronicamente constantes; 2) o significado da palavra muda, porém a realidade previamente apreendida por ela permanece constante. Portanto, a semântica deve encontrar uma nova forma de expressão com o fim de ajustar-se de novo fielmente à nova realidade; 3 ) as circunstâncias e o significado das palavras se desenvolvem separadamente, de maneira que a correspondência inicial não pode manter-se por mais tempo. Cf. KOSELLECK, Reinhart. Historia de los conceptos y conceptos de historia. Ayer - Revista de Historia Contemporanea, Madrid: Associación de Historia Contemporanea Marcial Pons, Ediciones de Historia S.A., n. 53, p. 31-32, 2004.

22 Joseph Moingt concebe que a tradição descamba para o tradicionalismo quando ela é objeto de inversão ao não se permitir "dizer de outra maneira o dizer original”. Cf. MOINGT, Joseph. Religiones, tradiciones y fundamentalismos. Selecciones de Teologia, v. 31, n. 122, p. 178, abril-junio 1992.

23 Exemplo dessa atitude se manifesta no projeto ideológico da revista católica Hora Presente, fundada em 1968 por José Pedro Galvão de Sousa e que será objeto de breves considerações neste artigo. 
pensam e agem do mesmo modo" 24 . Visto por um dos seus discípulos como "um dos maiores jusfilósofos do século XX" 25 , Galvão de Sousa contribuiu, enquanto professor de várias instituições de ensino superior católicas e autor de mais de duas dezenas de livros e centenas de artigos, para a disseminação dos princípios da filosofia do direito natural de base tomista, de teoria do Estado e da representação política sob a ótica do tradicionalismo corporativista. Algumas de suas obras, no entanto, servem como ancoragem para a doutrina da hispanidade por onde se articulam séries de subtemas, tais como o "estilo" do tradicionalismo hispânico sintetizado na excêntrica ou anacrônica adesão a um legitimismo monárquico de matriz carlista ${ }^{26}$, e, ao mesmo tempo, em poderosos argumentos apoiados no corporativismo e no nacionalismo católico. Que tradição é esta reivindicada por Galvão de Sousa e qual o papel do catolicismo como princípio formativo desta tradição?

O texto escrito por Eudaldo Forment como "Prólogo" à reedição de Idea de la Hispanidad, do filósofo Manuel García Morente, originalmente publicado em 1938, auxilia-nos a esboçar um breve percurso da palavra e dos seus $\operatorname{usos}^{27}$. Forment explica que hispanidade, no Diccionário de la Lengua

24 GALVÃO DE SOUSA, José Pedro. O pensamento católico e a democracia moderna. Convivium, ano II, v. III, n. 7, p. 14, setembro de 1963.

25 A opinião é de Ricardo Dip, Magistrado do Tribunal de Alçada do Estado de São Paulo, na Apresentação de: DIP, Ricardo. Tradição, revolução e pós-modernidade. Op. cit., p. XV. Quando Dip, em outubro de 1995, assumiu a cadeira 42 na Academia Paulista de Direito, entre outros encômios, referiu-se a Galvão de Sousa da seguinte maneira: "Se em breves palavras pudesse eu sumariar este vaso de eleição que foi José Pedro Galvão de Sousa, dele poderia simplesmente dizer: modelo do autêntico intelectual cristão. [...] a história de José Pedro é a de uma vida constante e serenamente cristã, é a biografia de um fiel progênito da Contra-Revolução". DIP, Ricardo, Elogio..., p. 77.

26 Conquanto seja um defensor dos princípios monárquicos, a remissão ao legitimismo carlista decorre da necessidade de Galvão de Sousa sustentar-se, doutrinária e teoricamente, num modelo político. Neste sentido, é esclarecedora para o propósito deste artigo a observação de que o carlismo, como assinalou Perfecto García, é a fonte de que se servem os tradicionalistas, tanto nos séculos XIX e XX, para apoiarem o legitimismo, isto é, a legitimidade ao trono espanhol de Carlos María Isidro, irmão do restaurador Fernando VII, em face das pretensões de Isabel, filha deste monarca. Segundo Perfecto García: "o carlismo não desaparecerá da Espanha, e continuará muito vivo e como uma alternativa ideológica na forma de tradicionalismo ao longo do século XIX e durante parte do século XX [...]”, influenciando, da mesma forma, movimentos tradicionalistas em países da América. Cf. PERFECTO GARCÍA, Miguel Ángel. O pensamento antiliberal espanhol: intelectuais e políticos antiliberais na Espanha do primeiro terço do século XX. In: LIMONCIC, Flávio; MARTINHO, Carlos Palmares. (Orgs.). Os intelectuais do antiliberalismo. Projetos e políticas para outras modernidades. Rio de Janeiro: Civilização Brasileira, 2010. p. 447.

27 FORMENT, Eudaldo. Prólogo. In: MORENTE, Manuel García. Idea de la Hispanidad. Madrid: Homo Legens, 2008. p. 7-77. Manuel García Morente (1886-1942), filósofo espanhol que ao final da vida (1937) converteu-se ao catolicismo e decide ser sacerdote. Durante largo tempo de sua atividade intelectual, agnóstico e seguidor de Ortega y Gasset, foi responsável pela introdução do kantismo, tradutor 
Española de 1926, remetia a "hispanismo", como um modo de falar peculiar da língua espanhola. Em edições seguintes, já na década de 1930, apareceram duas novas acepções: "Carácter genérico de todos los pueblos de lengua y cultura españolas" e "conjunto y comunidad de pueblos hispanos" 28 . Se desde então não tem havido modificação, sua apropriação pelos intelectuais foi alvo de sucessivas valorações e sentidos. Sobretudo, a intervenção do sacerdote argentino Zacarias de Vizcarra e a obra de pensadores espanhóis da generación del 98 se afirmam como fundamentos para celebrizar o termo, generalizando-o como um conceito e... uma narrativa mítica ${ }^{29}$.

Vizcarra propôs, em 1926, a "hispanidad" em substituição ao termo "raza", que se utilizava para comemorar o "Dia de la Raza" e a "Fiesta de la Raza" a 12 de outubro, em homenagem à memória de Cristóvão Colombo, servindo para "exteriorizar la intimidad espiritual existente entre la Nación descubridora y civilizadora y las formadas en el suelo americano [...]" e, igualmente, para não assinalar diferenças raciais que seriam inconvenientes aos diversos elementos integrantes das nações hispânicas ${ }^{30}$. A síntese da hispanidade em Vizcarra associar-se-á a uma variante religiosa quando o sacerdote, em diferentes situações entre os anos de 1941 e 1946, agregará sentidos mitológicos vinculados à figura materna da Virgem de Pilar. Vizcarra justificaria que a Virgem de Pilar fora a "Patrona de la Hispanidad", pela coincidência de o dia de descobrimento da América ser o mesmo da festa dedicada à primitiva igreja de Pilar. Vale, neste sentido, dar voz a Santiago de Vizcarra para que se observe a invenção dessa tradição que busca sua legitimidade na poeira dos tempos:

de Kant para o espanhol e pioneiro também pela recepção, na Espanha, da fenomenologia de Husserl e da axiologia de Max Scheler, além de profundo estudioso da filosofia de Henri Bergson. Seu texto clássico Idea de la Hispanidad, no qual faz profissão de fé e sistematiza uma "doutrina da hispanidade", foi publicado pela primeira vez no ano de 1938, na cidade de Buenos Aires, pela Espasa Calpe.

28 Idem, p. 71.

29 A generación del 98 espanhola, formada por intelectuais como Ramiro de Maeztu, Miguel de Unamuno, Azorin, Pio Broja e outros, traumatizada pelos desastres militares de 1898, que levaram a Espanha perder os restos ultramarinos do seu império - como Cuba e Filipinas - na guerra contra os Estados Unidos, colocou como pergunta obsessiva o que e qual era a identidade da Espanha. Segundo Forment, essa intelectualidade "Desembocó en una especie de enfermedad de autocrítica, que se ha denominado muy acertadamente 'patrimasoquismo', porque su patologia se manifiesta en lo que parece un goce en desvalorización y ataques e injurias a lo español". Ibid., p. 7.

30 Segundo Forment, a sugestão está dada no texto de Vizcarra "La Hispanidad y su verbo", publicado em Buenos Aires. Ibid., p. 8-10. 
El hecho especial directamente relacionado con todas las cristiandades hispánicas de ambos hemisferios es la maternidad originaria de su Fe y de sus Iglesias, maternidad que ostenta especialmente la Virgen Santísima bajo el título del Pilar, por el hecho de haber venido a España en carne mortal, como misionera de la fe de su Hijo y consoladora y alentadora del Apóstol Santiago y de sus discípulos, primer núcleo de la Iglesia Hispánica, de la cual tomo posesión al estilo romano, plantando en su suelo a modo de mojón posesorio, el Pilar de jaspe que por ministerio angélico, según antiquísima tradición aprobada por la Iglesia, trajo de Jerusalén y entregó a Santiago como base para edificar en su nombre el primer templo mariano del mundo. La advocación mariana del Pilar es la adecuada para la gran familia de naciones que se denomina Hispanidad, porque recuerda este hecho misionero especialmente relacionado con todos los miembros de ella, tanto los del Viejo Mundo como los del Nuevo ${ }^{31}$.

A semântica da hispanidade passaria a ser organizada em torno do núcleo simbólico de uma cultura cuja essência católica seria intensificada pelas concepções de intelectuais como Ramiro de Maeztu (1875-1936), Manuel García Morente e o integralista português António Sardinha ${ }^{32}$. Na sua Defensa de la Hispanidad (escrito em 1934), Maeztu a percebia como fundamento da unidade moral do gênero humano, geradora do humanismo espanhol, podendo a um só tempo conciliar igualdades essenciais a diferenças de honras e posições sem produzir conflitos. É necessário aduzir que Maeztu, por diversos momentos, reconstitui sua interpretação a partir da inspiração que lhe fornece Marcelino Menéndez Pelayo (1856-1912), para quem a hispanidade configurava necessariamente a hierarquização de

31 Ibid., p. 12.

32 António Sardinha (1887-1925), intelectual português convertido ao catolicismo e à monarquia em 1913. Fundou em 1914, junto com Xavier Cordeiro, Hipólito Raposo, Luís de Almeida Braga, Alberto de Monsaraz, José Pequito Rebello, João do Amaral e Rolão Preto o movimento Integralismo Lusitano, tradicionalista e monárquico. Para uma síntese de suas ideias restauracionistas e de defesa da doutrina da hispanidade, cf. SARDINHA, António. A aliança peninsular. Antecedentes e possibilidades. 3. ed. Lisboa: QP, 1972 (escrito em 1924). Sobre a trajetória intelectual de Sardinha, cf. DESVIGNES, Ana Isabel Sardinha. António Sardinha (1887-1925): um intelectual no século. Lisboa: Instituto de Ciências Sociais da Universidade de Lisboa, 2006. Uma síntese da história do integralismo lusitano pode ser lida em: COSTA PINTO, António. Os camisas azuis. Ideologia, elites e movimentos fascistas em Portugal, 1914-1945. Lisboa: Editorial Estampa, 1994. p. 23-92. 
seis grandes ideias: 1) fé católica; 2) monarquia tradicional; 3) latinidade (remetendo à conquista negociada pelo império romano, particularmente, em relação à linguagem e ao advento cristão) ${ }^{33}$; 4) liberdades populares (a partir de um primitivo núcleo público descentralizado, o município); 5) reprovação das ideias da ilustração; e 6) irmandade peninsular e hispânica ${ }^{34}$.

Chega-se, assim, à metamorfose operada por Galvão de Sousa, em face da contiguidade e do entorno ideológico favoráveis que sua reflexão apresenta na experiência dialógica com os autores espanhóis de extração tradicionalista. No seu Dicionário de Política, obra publicada post mortem e complementada por dois de seus seguidores, Galvão de Sousa expõe com relativa clareza a direção tomada quanto à significação de sua linguagem e o lugar central ocupado pela tradição hispânica no seu pensamento ${ }^{35}$. Um mergulho nos registros de verbetes inter-relacionados confere de partida a dimensão proposta: uma "restauração" da linguagem política, tendo como vértice a hispanidade, radicando dela, e somente dela, uma comunidade de termos análogos que reforçam o grau de compromisso com o tradicionalismo hispânico. Dessa forma, se observa que o termo hispanidade é o fio condutor para as seguintes terminologias que são explicitadas a partir dele: comunidade hispânica, comunidade lusíada, hispano-americanismo, lusitanidade. O conceito em Galvão de Sousa não designa simplesmente uma realidade física, mas a interação recíproca de natureza e cultura com predominância evidente da última. A cultura é devida aos modelos civilizatórios transmitidos por Espanha e Portugal; artífices de uma história sem conflitos ou contradições e que conserva sua unidade - ainda e mais no presente - resultante da adesão a ideais e valores comuns difundidos por missionários evangelizadores ${ }^{36}$. Esta síntese cultural resultaria num sentimento comum aos povos hispânicos do continente americano, brasileiros insertos, quanto ao autêntico significado de sua história, numa identidade

33 No Prelúdio que escreve à Defensa de la Hispanidad, Maeztu observa que "Durante veinte siglos, el camino de España no tiene pérdida posible. Aprende de Roma el habla con que puedan entenderse sus tribus y la capacidad organizadora para hacerlas convivir em el derecho. En la lengua del Lácio recibe el cristianismo, y con el cristianismo el ideal". MAEZTU, Ramiro de. Defensa de la Hispanidad. Buenos Aires: Ediciones Thau S.A./Ediciones del Cruzamante, 1986. p. 10.

34 Cf. Forment. Op. cit., p. 28.

35 GALVÃO DE SOUSA, José Pedro; GARCIA, Clovis Lema; TEIXEIRA DE CARVALHO, José Fraga. (Orgs.). Dicionário de Política. São Paulo: T. A. Queiroz, 1998.

36 Idem, p. 262-263. 
monolítica a defender. Somente existe a resistência temporal do significado porque ele foi marcado pela formação católica de tais povos ${ }^{37}$. Diante da importância crucial que representaria o catolicismo para os povos hispano-americanos, há uma recusa radical de Galvão de Sousa em aceitar um duplo desafio situado em tempos díspares e que se configura como grave ameaça à manutenção de um passado irretocável e a um presente que almeja, idealmente, preservar:

Devem ser tidos como espúrios e contraditórios os movimentos que se pretendem hispano-americanos, mas se fundamentam num indigenismo que exalta as formas pré-colombianas em detrimento dos valores cristãos. Da mesma forma, opõe-se ao hispano-americanismo e promove a sua destruição a chamada "teologia da libertação", inculcada como originária e específica na América Latina, mas baseada na dialética revolucionária marxista e procedente do pensamento teológico europeu de cunho modernista e progressista ${ }^{38}$.

Uma forma metodológica mais elaborada de desenvolver sua noção de tradição hispânica Galvão de Sousa encontrou no início da década de 1960, quando publicou o breve, mas significativo, O Brasil no mundo hispânico ${ }^{39}$. Trata-se originalmente de uma conferência pronunciada no Instituto Histórico e Geográfico de São Paulo sob o patrocínio do mesmo Instituto e da Casa de Cervantes, a 28 de abril de 1960, que demonstra a convergência conceitual e a leitura atenta que operava dos tradicionalistas da hispanidade. São reconhecíveis e nítidas, pelo menos, três variáveis que encaminham a reflexão de Galvão de Sousa sobre o presumível sentido da hispanidade:

1 - Adesão às teorias espiritualistas do nacionalismo hispânico: inspirado em Manuel García Morente e António Sardinha, Galvão de Sousa matiza as teorias naturalistas sobre a hispanidade que apenas consideram a identidade do ser hispânico enlaçada por categorias como sangue, raça,

37 Ibid., p. 264.

38 Idem, p. 264.

39 GALVÃO DE SOUSA, José Pedro. O Brasil no mundo hispânico. São Paulo: Herder Editora Livraria Ltda., 1962. 
território e idioma. Ao tratar a hispanidade não como uma unidade física, delimitada, mas espiritual, o intelectual católico defende uma "comunidade de nações vinculadas pelas afinidades históricas e por certas peculiaridades oriundas do legado que recebemos de Portugal e Espanha" "40. A vocação católica do hispanismo é expressa pelo projeto de transformação do Atlântico num autêntico mare nostrum, conforme a utopia de António Sardinha, "em que nós, hispanos da América, isto é, brasileiros e espano-americanos, pudéssemos chegar a constituir uma grande comunidade de povos pela mesma cultura" ${ }^{91}$. Sendo assim, os povos formados sob a cultura da hispanidade, cujo centro espiritual é o catolicismo, eram os verdadeiros portadores de uma concreta "personalidade cultural" originada na Hispania e continuada na América:

Na América, o homem hispânico foi portador de um patrimônio de cultura que transmitiu às novas nacionalidades constituídas pela fusão das raças aborígenes e, mais tarde, dos africanos e imigrantes, com portugueses e espanhóis, impondo estes os seus padrões éticos e assimilando os elementos culturais de outras raças. Ao contrário do que se dá com povos de outros continentes, tudo entre nós predispõe à união. Comuns procedências étnicas, afinidades linguísticas, a mesma fé religiosa, "tudo nos une, nada nos separa" 42 .

2 - Descentralização política fundada nos núcleos originários da comunidade: a descentralização é a essência da representação política no enfoque do tradicionalismo hispânico. A descentralização é a efetiva prática histórica das liberdades locais ou regionais traduzidas na sua desvinculação ou distanciamento da tutela do Estado. Ela se realiza por meio da valorização política de dois núcleos indevassáveis quanto à sua autonomia e às ingerências de um Estado centralizador. Esses dois núcleos são a família e a comunidade, que se constituem na origem do município e reúnem os chamados grupos intermediários formados na tradição do direito costumeiro (comunidade de vizinhos, associações de profissionais do mesmo ofício etc.). Esta seria, para Galvão de Sousa, a perfeita configuração das fidelidades

$\begin{array}{ll}40 & \text { Idem, p. } 10 . \\ 41 & \text { Ibid., p. } 25 . \\ 42 & \text { Ibid., p. } 51 .\end{array}$ 
políticas. Por quê? Porque a substância dessas fidelidades é construída por "relações concretas e reais" e não por "relações formais". Não há a mediação de abstrações normativas ou de uma instância de representantes. Esses dois aspectos resultariam na predominância de apetites políticos dos grupos alienados ou desinteressados pela vida da comunidade original.

Ao invés de reduzir a sociedade a um agregado de indivíduos em face do Estado, o que os levaria mais tarde a se agruparem em partidos, a verdadeira representação política, assinala Galvão de Sousa, é fruto dos interesses concretos dos homens tal como vivem em sociedade, quer dizer, nas famílias, na profissão, nas comunidades locais a que pertencem ${ }^{43}$. Sua crítica, obviamente, se direciona ao individualismo político das democracias baseadas no sufrágio universal igualitário, que suprime o voto por classe ou profissão, "fundamentando o poder político na vontade do povo-massa, constituído pelos cidadãos abstratos $[. .] "$.44 . O individualismo moderno, segundo Galvão, é uma visão anti-histórica que separa o homem de suas tradições e acaba por preconizar, para todos os povos, os mesmos regimes políticos e as mesmas constituições, sem levar em conta as particularidades diferenciadoras de cada comunidade nacional. Somente a visão hispânica é uma visão histórica do homem inserido numa tradição e pertencente a grupos naturais. Ela é também uma visão supra-histórica, de sentido transcendente: "O homem dessa concepção entranhadamente católica é o peregrino em demanda da Eternidade, o homo viator, a alma na busca ansiosa do Infinito" ${ }^{\prime 4}$.

Galvão de Sousa aprimora essa perspectiva corporativista em obras mais adensadas, tais como: Da representação política e $O$ estado tecnocrático ${ }^{46}$. No entanto, parece que estamos novamente a ouvir a voz de García Morente falando à consciência do intelectual católico no que toca à democracia e à "farsa" do parlamentarismo. Na já citada Idea de la Hispanidad, o filósofo espanhol descreveria a personalidade do "caballero español”, bem como pontuaria distinções entre vida pública e vida privada que são profundamente coincidentes e inspiradoras a Galvão de Sousa:

43 Cf. Galvão de Sousa. O pensamento católico e a democracia moderna. Op. cit., p. 6.

44 Cf. Galvão de Sousa. O Brasil no mundo hispânico. Op. cit., p. 41.

45 Ibid., p. 42.

46 Cf. GALVÃo DE SOUSA, José Pedro. Da representação política. São Paulo: Saraiva, 1971. Cf. também: GALVÃO DE SOUSA, José Pedro. O Estado tecnocrático. São Paulo: Saraiva, 1973. 
El caballero español no siente y cuase no comprende la relación abstracta: por ejemplo, la de ciudadania pura o la pura humanidad. Necesita cuanto antes al otro, hacerse amigo - o enemigo - del otro. Establecer con el otro una relación que se funde en la singular persona del otro y no en su simple carácter de hombre, o de ciudadano. Por eso entre españoles el trato puede más que el contrato... [...]. Al caballero cristiano le es, en el fondo de su alma, profundamente antipático todo socialismo, o sea, la tendencia a vaciar en moldes de relación e vida públicas lo que por esencia constituye el producto más granado de la persona particular, real y viviente. En esta concepción de la vida privada hay, sin duda, hoy, cierto anacronismo, Pero no sabemos si por retraso o por adelanto. Algunas de las consecuencias que de esta concepción se derivan, cuentan entre las naciones más adelantadas del momento actual. La hostilidad profunda del caballero español a todo formalismo falso, se compadece mal, claro está, con esto que se va llamado democracia y con la ridícula farsa del parlamentarismo ${ }^{47}$.

Em síntese, o papel secundário da entidade Estado visa destituí-lo de monopólio e concentração de poder em favor de um conceito orgânico direcionado a erigir uma sociedade estratificada em classes, a cada uma correspondendo uma função determinada ${ }^{48}$.

3 - Crítica à europeização: a europeização significa a invasão da política burguesa, do pensamento revolucionário, da irreligião, do progressismo, do protestantismo, da maçonaria, do jacobinismo, do liberalismo e do capital financeiro na medula da nação. Embora haja limitada resiliência quanto ao fato de considerar a cultura hispânica como um ramo da cultura europeia, existe "um momento histórico em que os valores substanciais desta se desagregam, enquanto aquela, a cultura hispânica, continua a conservá- los"49. Galvão de Sousa deseja explicar que os valores da cristandade não se coadunam com os da Europa "protestantizada e racionalista", submetida

47 Cf. Manuel García Morente. Op. cit., p. 263-264, p. 281-282.

48 Cf. GONZÁLEZ CUEVAS, Pedro Carlos. El pensamiento político de la derecha española en el siglo XX. De la crisis de la Restauración al Estado de partidos (1898-2000). Madrid: Tecnos, 2005. p. 44. Lembremos que a concepção corporativista de sociedade em Galvão de Sousa é tributária da visão católica, de onde ecoam os princípios da doutrina social da Igreja.

49 Cf. Galvão de Sousa. O Brasil no mundo hispânico. Op. cit., p. 30. 
a um processo de desagregação religiosa e política desde o humanismo. Em sua opinião, enquanto Espanha e Portugal, dilatadores da "Fé e do Império", alargaram os horizontes da cristandade, tornando-se povos missionários, os europeus do norte, com a secularização em processo desde o século XVI, consagraram - possivelmente ao longo século XIX - um direito internacional baseado no sistema egoístico de equilíbrio de potências, em lugar da ordem ecumênica das tradições da cristandade ${ }^{50}$.

Por fim, a crítica à europeização implicará também na visão distinta entre o individualismo hispânico e o individualismo europeu, protestante. Vejamos. O individualismo hispânico se integra ao sentido transcendente da vida sem negar a individualidade concreta. O ser hispânico recobre "o homem de família, da localidade urbana ou campestre, da região, de uma tradição nacional, e ao mesmo tempo fiel, que pertence ao Corpo Místico"51. $\mathrm{O}$ individualismo passará a ser, então, o grande apreço ao valor da pessoa humana. Ao contrário, o individualismo protestante (europeu) é rebelde: contra o magistério infalível, irá separar o fiel da comunidade eclesiástica, para fazer a vida religiosa depender do livre exame, ou seja, da razão de cada um. Daí derivam os outros males sociais:

O individualismo liberal, na ordem econômica, com a livre concorrência e a lei da oferta e da procura, instaura as relações abstratas entre vendedor e comprador, produtor e consumidor, empregador e empregado. O individualismo político das democracias baseadas no sufrágio universal igualitário suprime o voto por classe ou profissão, fundamentando o poder político na vontade do povo-massa, constituído pelos cidadãos abstratos e desvinculados das pequenas comunidades, quais sejam a família, o município ou a associação profissional ${ }^{52}$.

É de notar que tais argumentos não vicejam de escombros ideológicos. Eles estavam presentes na constelação heterogênea de projetos políticos do grupo de intelectuais que tentou construir um novo Estado antiliberal na Espanha, a partir da ditadura de Miguel Primo de Rivera y

50 Ibid., p. 31-32.

51 Ibid., p. 40.

52 Loc. cit., p. 41. 
Orbaneja (1923-1930), avançando franquismo adentro. O que ligava esses grupos, segundo Perfecto García, eram o antiliberalismo, o catolicismo, o corporativismo e a defesa de um regime ditatorial autoritário, oposto tanto ao liberalismo democrático quanto às ideologias - consideradas estrangeiras e antinacionais - do socialismo, comunismo e anarquismo ${ }^{53}$. Elas seriam formas europeizantes de desnacionalização e fragilização da religião tradicional: enquanto a hispanidade era indissociável à tradição, o liberalismo e suas corruptelas se relacionavam com a Europa e as ideologias exóticas.

Galvão de Sousa foi um entusiasta da ditadura militar e chegou a flertar com o regime no propósito de inserir-se na condição de "intelectual orgânico" e contribuir para que princípios da doutrina tradicionalista pudessem estar incorporados, inclusive, na ideologia de segurança nacional ${ }^{54}$. No entanto, este seu intento teria sido freado pela repugnância dos militares a certo tipo de intelectualismo que não se combinava com a intenção - ou falta de intenção - da ditadura, que enveredou a prestigiar uma tecnocracia de direita. Galvão de Sousa recuou desse desejo, todavia, sua colaboração fez-se por meio do periodismo católico, ao fundar, em 1968, a revista Hora Presente, que se transformaria no reduto, por assim dizer, do discurso da hispanidade e sob controle de muitos integristas católicos contrariados com o avanço da teologia da libertação, bem como com a participação de muitos religiosos na firme oposição à ditadura, denunciando prisões ilegais, torturas e desaparecimentos.

A revista Hora Presente reunirá, sob a liderança de Galvão de Sousa, os intelectuais que podemos designar de neotradicionalistas (Rafael Gambra, Juan Vallet de Goytisolo, Elías de Tejada, Eugenio Vegas Latapié) e que absorveram nas fontes do tradicionalismo hispânico do primeiro terço

53 Para a década de 1920, Perfecto García elenca três correntes ideológicas básicas na Espanha, munidas, é verdade, de projetos distintos, mas que consagravam alguns princípios coincidentes: o tradicionalismo, representado pelos escritores e políticos Victor Pradera, Juan Vázquez de Mella e pelo poeta José María Peman ou por José Pemartín e por Ramiro de Maeztu; a corrente social católica, liderada por Ángel Herrera Areja; e uma direita mais radical, representada por Eduardo Aunós ou Ernesto Gimenez Caballero. José Pedro Galvão de Sousa terá como leituras de cabeceira, até onde pude constatar, os intelectuais da primeira corrente. Cf. PERFECTO GARCÍA, Miguel Ángel. O pensamento antiliberal espanhol: intelectuais e políticos antiliberais na Espanha do primeiro terço do século XX. Op. cit., p. 461.

54 Ver, neste sentido, a posição apaixonada e apologética, portanto, parcial, da tese de José J. Albert Márquez. Op. cit., p. 34-35. Galvão de Sousa esboça essa doutrina dois anos antes do golpe militar. GALVÃO DE SOUSA, José Pedro. A problemática da segurança nacional. Convivium, p. 29-43, julho/ agosto 1962 . 
do século XX seus princípios elementares, reatualizando-os para o contexto de referência, diga-se, bastante dramático. Haverá, neste sentido, o envolvimento profundo de muitas hierarquias religiosas e elites tradicionalistas com a parte mais obscura das ditaduras militares do cone sul, assim como recrudescerá o conflito irremediável entre a posição tradicionalista e os novos horizontes doutrinários e teológicos trazidos pelo Concílio Vaticano II, a luta acirrada entre aqueles chamados de progressistas - nomenclatura que designa os neomodernistas católicos - e os tradicionalistas adeptos intransigentes da doutrina da Igreja pré-Concílio Vaticano II.

\section{Considerações finais: tradicionalismo hispânico na modernidade ibero-americana}

Há pertinência no argumento de Jorge Myers ao assinalar que os tradicionalistas seriam pouco convincentes para sustentar que a cultura intelectual latino-americana existe em uma relação de perfeita continuidade com a tradição medieval dos povos da Península Ibérica ${ }^{55}$. Recorde-se, como demonstrado, que a continuidade é uma das ideias-força a amparar o projeto intelectual de Galvão de Sousa em relação à "hispanidade". Não obstante, deve-se indagar em que medida o projeto alcança ressonância ou estabelece rastros, enquanto tradição residual diante das tradições emergentes, nas atuais demandas dos grupos conservadores, seja nas políticas sociais ou no encaminhamento do debate público entre princípios religiosos e princípios da modernidade laica apoiada no suposto de consolidação do mundo secularizado. Quanto ao propósito específico deste artigo, o foco predominante da historiografia parece centrado no papel das elites modernizadoras enquadradas na tradição ibero-americana ou no iberismo americano. Esta classificação valoriza ou enfatiza o papel das vanguardas americanas orientadas pelo pensamento laico e pelas ideologias seculares,

55 MYERS, Jorge. Los intelectuales latinoamericanos desde la colonia hasta el inicio del siglo XX. In: ALTAMIRANO, Carlos. (Dir.). Historia de los intelectuales en América Latina. I. La ciudad letrada, de la conquista al modernismo. Buenos Aires: Katz Editores, 2008. p. 30. 
cuja aspiração, desde o século XIX, seria encontrar uma estrutura de poder compatível, uma determinada ordem ou discurso que pudessem ser institucionalizados e aplicados como resposta às necessidades de combater o atraso social, econômico e político ${ }^{56}$. Para Galvão de Sousa, como intelectual católico tradicionalista, tal interpretação seria completamente inviável. Ele tem como expectativa o retorno do tempo perdido da universalidade cristã medieval sob hegemonia hispânica, uma Universitas hispanorum colada à cultura estabelecida pelo projeto colonizador que escapa à experiência de uma racionalidade anglófona, ou rejeita o legado político, cultural e ideológico que tem seu ponto de partida na revolução francesa. Pouco convincente? Talvez, mas improvável que deva ser negligenciado ou lançado ao exílio antes do cotejamento com as expressões modernizadoras ou antes do empenho por reconstituir tal problemática à luz das variações assumidas pelo discurso tradicionalista e de sua correspondente atualização. Os tradicionalistas tendem a repugnar a terminologia "iberismo". Isto fica claro no postulado de Galvão de Sousa a partir do intercâmbio de sua realidade e as doutrinas que recepciona no ambiente brasileiro. Ele rebaixa o iberismo (coisa de liberais e socialistas) para elevar o hispanismo, como uma "aliança peninsular" estendida aos povos "hispano-americanos", sem a supressão das soberanias nacionais, mas com a cooperação efetiva, desde que ela se dê em conformidade com alguns parâmetros: catolicidade, desigualdades naturais, municipalismo, aliança contra o comunismo. É esclarecedor o que Galvão de Sousa propõe como alternativa ao "equivocado" emprego de ibero-americanismo:

Hispanismo é bem a palavra adequada, segundo a designação da Península desde remotíssimos tempos, com os diferentes povos que a habitam abrangidos no termo Spania. O adjetivo "hispânico" refere-se a todos esses povos, entre os quais os ibe-

56 Refiro-me a alguns prestigiosos e indispensáveis trabalhos dos historiadores e sociólogos que privilegiam o ibero-americanismo como fundamento aos projetos de modernização e secularização. Cf.: ALTAMIRANO, Carlos. (Dir.). Historia de los intelectuales en América Latina. I. La ciudad letrada, de la conquista al modernismo. Buenos Aires: Katz Editores, 2008. ALTAMIRANO, Carlos. (Dir.). Historia de los intelectuales en América Latina. II. Los avatares de la "ciudad letrada" en el siglo XX. Buenos Aires: Katz Editores, 2010. BEIRED, Jose Luis Bendicho. Intelectuais e imprensa: a configuração de uma rede hispano-americana no espaço atlântico. História, São Paulo, v. 28, n. 2, p. 821-836, 2009. PRADO, Maria Emília. (Org.). Tradição e modernidade no mundo ibero-americano. Rio de Janeiro: CNPq, 2004. 
ros. O vocábulo “ibérico" é, pois, de significação mais restrita, prestando-se, além dos mais, a renovar os equívocos suscitados pelo iberismo, que liberais e socialistas apregoavam, em fins do século passado, num contraste flagrante com a tradição das Espanhas. Da mesma forma, à expressão ibero-americanismo, ainda usada, deve preferir-se, por motivo de precisão na linguagem, hispano-americanismo, que alguns, erroneamente, limitam à América espanhola. Na verdade, a América hispânica inclui os países da América espanhola - digamos espano-americanos - e o Brasil. Hispanos somos também nós, por sermos dependentes dos hispano-portugueses, e esta denominação, que corresponde à realidade da nossa formação racial e histórica, está hoje consagrada $^{57}$.

Galvão de Sousa pretendeu dar continuidade e consistência ao projeto de resistência tradicionalista católica - e nostálgica - ao insistir na ideia limite de que era necessário construir alianças hispano-luso-brasileiras, tendo em conta a origem étnica, cultural e religiosa comum na história dos povos, e isto, possivelmente, poderia se realizar no marco constitucional-legal pela refundação de uma utopia católico-política transnacional. As premissas do iberismo apresentavam, na ótica do intelectual, sérias disfunções que iam do jacobinismo inerente à cultura moderna, passando pela abstração do parlamentarismo, para chegarem à violência revolucionária e à implantação de um Estado totalitário. Mas estas, como reiteram os historiadores, são hipóteses para contarmos as próximas histórias.

Recebido em janeiro de 2011. Aprovado em abril de 2011.

57 Cf. Galvão de Sousa. O Brasil no mundo hispânico. Op. cit., p. 25-26. 